\title{
Los Perimontun (Visiones) en la Cultura Mapuche (con especial referencia a cómo ocurren entre los Pewenche del Alto Bío-Bío)
}

\author{
Perimontun (visions) in Mapuche Culture (with particular reference to their occurrence \\ amongst the Pewenche of the Alto Bio-Bio) \\ Gilberto Sánchez C.
}

\begin{abstract}
RESUMEN
Tradicionalmente los mapuches han experimentado el llamado perimontun, o "visión". Tal como aparece documentado, es como un milagro, un agüero negativo, un prodigio, algo incluso sobrenatural (una señal de la divinidad), un hecho extraordinario, experimentado por algunos miembros de las comunidades. En tiempos comparativamente más recientes, el perimontun ha sido algo más privativo de los (las) machis, quienes, durante esas "visiones" serían llamados por la divinidad para ejercer su oficio. En la comunidad de Cauñicú, en el Alto Bío-Bío (VIII región), el perimontun ha sido experimentado por algunas personas cuando un wekuvü, que puede ser malo, pero también bueno, actúa sobre ellos. Cuando ocurre, pierden el sentido, la lucidez, la razón, la orientación en el tiempo y en el espacio. Es como un sueño despierto; sin embargo, se trata de una experiencia real vivida, la cual puede ser negativa, pero también positiva. En el primer caso, el sujeto puede llegar a morir; en el segundo, no le ocurre nada malo e, incluso, puede recibir un golpe de suerte (küme pülliü). Según afirman algunos, antes cuando la gente era 'mora', no bautizada, se daba con mayor frecuencia el perimontun; en la actualidad, solo ocasionalmente. Los relatos sobre "visiones" son considerados ngütram, es decir, denotan hechos reales y no ficticios como los epew, en los cuales interactúan animales que dialogan entre ellos.
\end{abstract}

Palabras Clave: Cultura Pehuenche, Creencias Ancestrales, Perimontun (“Visiones”) de la Gente, Wekuvü Malo y Bueno.

\begin{abstract}
Traditionally, the mapuche have experienced what are called perimontun, or "visions". This has been documented as a miracle, a negative omen, a prodigious feat, even something supernatural (a sign of divinity), an extraordinary occurrence experienced by some members of the communities. In more recent times, the perimontun has tended to be exclusive to the machis, who, during these "visions" are called upon by the divine to practice their vocation. In the community of Cauñicú, in the Alto Bío-Bío of southern Chile, the perimontun has been experienced by some people when a wekuvü, which can be bad, but also good, holds sway over them. When this occurs, they lose feeling, lucidity, reason, and orientation in time and space. It is like a waking dream; nevertheless, it consists of a real lived experience which can be negative but also positive. In the first case, the
\end{abstract}

i Profesor emérito (Lingüística) de la Universidad de Chile. Departamento de Lingüística. Correo-e: gsanchez@uchile.cl 
subject can eventually die; in the second, nothing bad happens, and a stroke of luck may be received (küme püllüi). According to what some claim, in past times when the people were moros, not baptized, the perimontun were more frequent; in the present day, they are only occasional. Stories told about "visions" are considered ngütram, which is to say they denote real events rather than fictitious ones like the epew, in which animals are involved and are seen to dialogue among themselves.

Keywords: Pewenche Culture, Ancestral Beliefs, Perimontun (“Visions"), bad and good Wekuvü.

Ya en las gramáticas coloniales del mapuche -llamadas entonces artes- encontramos información sobre el perimontun,llamado también perimuntun, perimontu y perimol. Según el P. Luis de Valdivia (Vocabulario) perimuntun es "el milagro cosa que admira mucho" y también "agüero malo"'. Según el P. Andrés Febrés, "Perimol, perimontu -alguna cosa extraordinaria, que se ve, ò Pexe, ò Paxaro, ò rebentazon de volcan \& c.it. milagro, qualquiera cosa sobre las fuerzas de la naturaleza, ò cosa que nunca se ha visto" y "Perimoln, perimontun -haber, ò suceder de esto, ò verlo” (Febrés I765, Calepino: 587); "Milagro, milagrosa cosa- perimol, perimontu" (Febrés 1765, Vocabulario: 37I). Según el P. Bernardo Havestadt, "Perimon, perimol, perimontu, res mira, mirabilis, prodigio similis: miraculum. perimoln, perimontu, edi miracula, prodigia..." (Havestadt I883, Chilidúǵu II: 742)². Solo según el P. Valdivia, podía tratarse de algo malo; según sus cofrades posteriores no era -al parecer- algo negativo. Ninguno de esos autores consignó si el perimol o perimontu era experimentado por cualquier persona, o solo por algunas (por ejemplo, un/a machi). En autores modernos las referencias suelen ser breves y no ahondan mayormente al respecto. El Dr. Rodolfo Lenz, además de consignar la información del $\mathrm{P}$. Febrés, afirma que, en la Frontera, el perimónto [sic] es un "fenómeno estraordinario, de mal agüero, ( $p$. ej., una gallina que canta como gallo, hai que matarla porque es perimonto)". (Lenz I905-1910: 574). Según Tomás Guevara (1908: 246) perimontu son hechos sobrenaturales que algunas machi han visto, como piedras que saltan, animales míticos que cruzan el espacio. Además, "Espresa el mapuche el hecho de ser hablado mientras duerme, por alguna persona, animal u objeto con la palabra perimontun (cosa sobrenatural)" (Guevara 1908: 314). Más adelante agrega “...perimontun. Desígnase con esta voz todo hecho contrario a las leyes naturales, como el movimiento de un cuerpo en reposo sin una fuerza que lo impulse, el humo de una piedra que no está en contacto con el fuego" (Guevara 1908: 324). El P. Félix J. de Augusta consigna perimol "el mal de agüero, presagio malo", perimolkalen "tener presagios malos" y perimoltun "haber tenido un presagio malo"; también perimontu "la visión" y perimontun "tener visiones (v. gr. las machis); asustarse los animales cuando notan algo"; además "asustarse con alguno; v. gr:: Iñche perimontueneu trewa. Conmigo se asustó el perro" (Augusta 1916, Diccionario I: I70-I7I). R. Latcham (1922: 67I), por otra parte, identifica al perimontu con el fetiche salvador o protector, adquirido o encontrado (pen, hallar o adquirir; montu salvador ${ }^{3}$, protector; montuln salvar o librar a otro). B. Kössler-llg (1962: 8I) consigna que "un agüero especial es el perimontuln o perimol, consistente en trastornos inusitados de la naturaleza". En la obra de M. Titiev (I95I:8I) solo se encuentra una referencia, y se trata también de un tipo de "visión", en la cual una mujer de edad, en raras ocasiones, es poseída por una bestia sobrenatural que la deja embarazada. En Faron (1964: 67), se encuentra el término perimo (ivariante de perimol?), el cual denota a un pájaro nocturno de aquellos que, al pasar sobre las casas, en la noche, 0 gritar cerca de ellas, presagian desgracia y muerte.

Según P. Coña (1973), cuando la divinidad deseaba que se celebrara una rogativa, se manifestaba mediante un perimontun, el cual era experimentado por algunas personas. En vista de que, en tales visiones ocurrían cosas fuera de lo común, por ejemplo que había bajado un toro negro desde el volcán, que este iba a hacer salir el mar, que había hablado una vaca, los miembros de la comunidad hacían los preparativos para llevar a cabo la fiesta (kawiñ) del guillatún ${ }^{4}$. 
Martín Alonqueo (1985), por su parte, informa que el o la machi era poseído/a por el espíritu fileu, el cual se manifestaba a través de un sueño o de un perimontu, es decir, una visión, una cosa extraña, que significaba un aviso. Una niña recibía revelaciones por medio de un perrimontu: veía un corderito blanco en un pajonal. La visión podía anunciar a una persona tanto un mal augurio como uno bueno (Alonqueo 1985: 48, 50, I0I).

En la actualidad el perimontun sería experimentado tanto por machis -donde hay- como por cualquier mapuche. Al respecto, escribe A. M. Bacigalupo (200I: 33): “Algunas machi son llamadas a su profesión a través de visiones especiales llamadas perimontun, en las cuales ven a sus espíritus auxiliares. Siempre hay algo inusual en este encuentro que lo distingue de un evento ordinario. Por ejemplo, animales inmóviles, agua brillante, luz extraña y enfermedad repentina de la neófita. Por lo general las machi tienen visiones de un toro o un caballo, de una serpiente cerca de un canelo, de pisar a una serpiente (significando que van a ser ricas) y de sus símbolos rituales. Estas visiones generalmente van acompañadas por sueños de sus implementos rituales, de dioses, espíritus y a veces versiones del Dios cristiano, de la Virgen, de caballeros armados y trompetas".

En el Alto Bío-Bío, y particularmente en la comunidad de Cauñicú -donde no hay machis desde hace mucho tiempo-, el perimontun es una "visión" que experimentaban -y todavía experimentan- algunas personas, a las cuales un espíritu -un wekuvï, que puede ser tanto malo como bueno ${ }^{5}$ - les ocasiona un tipo de perturbación. La experiencia puede ser negativa, o positiva. En el primer caso, cuando el espíritu domina completamente a la persona, esta puede trastornarse 0 , incluso, morir de una manera inexplicable ${ }^{6}$; en el segundo, puede ser una especie de premonición de algo bueno que se producirá después, un golpe de suerte, por ejemplo; también puede ser, en definitiva, un episodio sin consecuencias. Cuando alguien experimenta un perimontun, pierde el sentido, la lucidez, la razón, la orientación en el tiempo y en el espacio (upay iñ duam) mientras dura y, por consiguiente, no está en sus cabales; cuando termina la "visión" (kimkonlu reke vemngechi) le parece que nada ha ocurrido, que todo está como hasta el momento antes de producirse el hecho. Sin embargo, sus efectos posteriores, negativos o positivos, demuestran que se trata de una experiencia real y no, por ejemplo, de un sueño (pewma). Si se tiene una "visión" hay que rezar (ngillatún) a Chaw Ngünechen (el Padre que gobierna a los hombres), o persignarse; entonces el espíritu se aleja. Antes, según decían los finados mayores (püttake che yem), los perimontun eran muy frecuentes porque la gente era mora, es decir, no bautizada. "Antes pasaba eso -el perimontun- porque había personas que no tenían agua (ngekelay ta che ta tukukolelu), entonces esa alma (inamongen) no subía a la Gloria (Cielo), sino que quedaba en la tierra, en la oscuridad (dumiññawki), penando para siempre. Entonces, muchas veces se aparecía a las personas, o se escuchaba algún ruido, o una voz. También ocurre cuando una persona piensa mal, entonces muchas veces se realiza ese pensamiento. Cuando uno muere, si es moro el inamongen se queda aquí abajo, anda en la oscuridad; en cambio, si es bautizado, su inamongen está reconocida por el Señor y, si es buena, se va la wenumapu (La tierra del cielo)" (R. Naupa). Dado que actualmente la mayoría de la gente es bautizada, los perimontun son menos frecuentes.

Los relatos sobre perimontun -que todavía se conservan- son considerados ngütram (conversa sobre un hecho real) y no un epew.

\section{RELATOS DE “VISIONES”}

Consignamos cinco textos que se refieren a "visiones" experimentadas por diferentes pewenche, narradas en chedungun del Alto BíoBío, recolectados en la comunidad de Cauñicú. Para transcribirlos empleamos el Alfabeto Mapuche Unificado, al cual hemos agregado el grafema $\mathbf{v}$ para representar el fonema labiodental fricativo sonoro oral $/ \mathbf{v} /$ que ocurre en esa variedad dialectal del mapuche, en lugar de /f/ labiodental fricativo áfono oral que ocurre, por ejemplo, en comunidades pewenche del sector sur (por ejemplo, en Panguipulli) ${ }^{7}$.

Las frases de los relatos se unen por medio de los elementos ilativos veymew veymu vey, veymew veyta, veymew veymu vemngechilu, vemngechilu vey, vemngechilu vey ta, vey 
vemngechilu, vey vemngechilu vey ${ }^{8}$. En cuanto a su función, además de unir los segmentos del relato, mantienen viva la atención y la expectación, en los oyentes, por el desarrollo del relato. Como es un discurso oral, se podría decir que el narrador "se sostiene", "se afirma" en tales elementos. Seguramente también por ello tienen una alta frecuencia.

Como los hechos narrados han ocurrido en un pasado -remoto o cercano- y quien los cuenta no los presenció y los conoce solo "de oídas", emplea también con mucha frecuencia el impersonal piam "dicen", "se dice" y el morfema sufijo reportativo -rke- "dicen que”. Cuando se da uno, no se da el otro, y viceversa.

Nuestra traducción es semilibre, a fin de no traicionar la versión original. Respecto de los elementos ilativos, como igualmente de piam y rke-, solo los hemos traducido al español cuando nos ha parecido necesario. Los textos se recargarían con demasiados "dicen que dijo", "dicen que", etc., y afectarían su fluidez. En pro de esta fluidez hemos agrupado varios macrosegmentos, a partir de 0 y I. Hemos realizado las traducciones con la valiosa ayuda de varios hablantes competentes en chedungun, pero la versión definitiva es de responsabilidad nuestra.

\section{El espíritu de la polola muerta}

\section{(Narrado por Ramón Naupa Epuñán "Likanan"9 el 19.04.1988.)}

Un mapuche "achilenado" tenía una polola en la cordillera, a la cual solía visitar. Una vez la fue a ver en la época cuando caen los piñones y la gente va a recogerlos (marzo). Demoró un día en llegar. Cuando llegó no vio gente, pero salía humo de la casa y había un perrito. Cuando entró en la casa, estaba sentada su polola, pero tenía la cara tapada con un rebozo y le daba la espalda. Le preguntó por su gente; dijo que se habían ido, pero que vendrían a buscarla. Le ofreció que se sentara, pero siempre tenía los ojos tapados y le daba la espalda. El hombre pensó que quizá le tenía vergüenza. Como iba a alojar, ella le dijo que amarrara su caballo, y que no se fuera. El joven ya estaba intranquilo y pensando en irse. Salió a amarrar su caballo, y volvió a entrar en la casa, donde estaba su polola. Ella estaba tostando piñones, pero dándole la espalda. Luego le pasó piñones para que comiera; estaban (quemados) como carbón. El hombre se preguntaba por qué estaba así. Ella no lo miraba, pero él sí. Entonces acertó a mirar hacia arriba, y vio su cadáver sobre el fuego. Entonces sintió mucho miedo. Con el pretexto de ir a desensillar su caballo, salió. Ella le dijo que esa noche la llevara (de ahí). La niña no lo soltaba. Cuando salió de la puerta miró hacia atrás y le vio los ojos: jestaban huecos! Pensando huir de ahí, apretó la cincha de su caballo. La mujer ya lo estaba mirando y casi había salido de la casa. Entonces salió galopando y, detrás persiguiéndolo, la mujer. Casi lo alcanzó. Él la alejaba borneando un lazo que llevaba. Así, llegó hasta donde había una lenga; saltó rápido hacia la lenga y subió gateando, hasta llegar a la punta del árbol. La mujer llegó y miró hacia arriba. Entonces llamó a gritos a "El que mira hacia arriba", al "Costilla rota" y al "Sombrero verde", para que cortaran el árbol. Llegaron los hombres, cada uno con su hacha, y comenzaron de inmediato a cortar el árbol. El hombre escuchaba los golpes dados con las hachas. El "Costilla rota" empujó varias veces el árbol. Según decían, el joven ya iba a caer. Movían el árbol donde estaba el joven, el cual tenía mucho miedo, y no sabía qué hacer. Pasó ahí la noche. Entonces sintió deseos de orinar, y les lanzó la orina. Los hombres dijeron que les estaba lloviendo. "-iYa pronto va a caer!", decían, y seguían dando hachazos. El joven sintió ganas de defecar, y se los dejó caer. Los hombres dijeron que estaba nevando. Estuvo toda la noche ahí, y los hombres seguían cortando. Pero, al alba, cantó el búho quilquil y, como le tenían miedo, decidieron irse. Se quedaron callados -la niña también- y se fueron. Cuando asomó la aurora, no había nada. Su caballo estaba ahí mismo; no se había ido. Entonces bajó del árbol y miró donde habían estado cortando. No le había pasado nada; no tenía ninguna seña. Solo estaba lo que él les había dejado caer (desde arriba). Entonces regresó a su casa, a caballo.

Según conversaba el joven, “El que mira para arriba" es el alma de quien se ahorca; el "Costilla 
rota" es el alma de quien muere apuñalado, y el "Sombrero verde" es el alma del que muere de improviso.

\section{Así fue la "visión” que tuvo.}

\begin{tabular}{|l|l|}
\hline $\begin{array}{l}\text { 0. Vey ta amulaviñ tüvachi } \\
\text { perimontun ngütram. }\end{array}$ & $\begin{array}{l}0 \text {. Ahora voy a contar esta } \\
\text { conversa de una 'visión'. }\end{array}$ \\
\hline
\end{tabular}

I. Kuyvi nütramkaki tayñi ñuke yem $^{10}$ vey mülerki kiñe weche wentru piki vey kulngenkerkil" niekerki ta kiñe domo tayñi kulngenkel. -Veymew wingkañma ${ }^{12}$ wentrurke, piki. Vey ta küpakerki kulngenal. -Veymew yattengen, piki. Vey amurki ti pu che pewen mew tayñi ngülliwmeal. Veymew powürkingün.

I. Antes conversaba mi finada madre $^{13}$ que había un joven que pololeaba; dicen que tenía una mujer con la que pololeaba. Era un mapuche "achilenado", decía. Solía venir a pololear. -Era el tiempo cuando suelen caer los piñones ${ }^{14}$, decía, y la gente iba a la pinalería a piñonear ${ }^{15}$. Entonces llegaban hasta allá.

\begin{tabular}{|l|l|}
\hline 2. Veymu ti wentru allkülu & 2. Entonces, cuando el hombre \\
küparki pepaial tayñi & oyó (que fueron) vino a ver a \\
kulngenkelchi domo. Kiñechi & la mujer con la que pololeaba. \\
ngepalu pepay vey amutuy. & $\begin{array}{l}\text { Una vez vino a dar, (la) vio y se } \\
\text {-Vey travken, piki, vey ká }\end{array}$ \\
fue. -Era otoño, decía. Luego \\
wiñorki nga ká pepaial tayñi \\
kungenkelchió para ver otra vez a su \\
polola.
\end{tabular}

3. -Veymew akulu vey upaantü akurki, piki. Vey peparkelay che. Veymew varvarkülekarki kütral ti ruka mew ka kiñe püchi trewa mülekay, pirki. -Veymew püchi üngkütripa nagkollupan vey konpon, pirki weche wentru. -Veymu allongkopalu inche vey veymu anüli tayñi domo iñ kulngenkel, pirki. -Chikeltuli, takunii ñi ange, oñonküli.Vey -kidulepi nay tayñi domo ñi kulngenkel ta tüva, pirki ti weche wentru.

4.Vemngechilu vey dungulparkevi, dungulngerki. Veymew ramturkevi tayñi pu che vey -Tayi amutuingün, pirki, vey -inche mülen ta ta mew vey ta yepatungeal ula inche, pirki. Veymew vemngechilu vey ta anülngerki, welu pengenelaanu ange tayñi domo, pirki ti weche wentru, oñonyawlelenu, takuyawlüy ñi nge chikel mew.
3. -Cuando vino demoró un día en llegar, decía. Dicen que no vio gente. -Entonces estaba todavía humeando el fuego en la casa y había un perrito, decía. -Entonces, me bajé al frente, del caballo, y entré, decía el joven. -Cuando me asomé, estaba sentada ahí mi polola, decía; tenía la cara tapada con el rebozo, estaba dando la espalda. Estaba sola la mujer con la que pololeaba, pues, decía el joven.

4. Así las cosas, le habló. Entonces le preguntó por su gente. -Hace poco se fueron, dijo. -Yo me quedé aquí, y después me van a venir a buscar, dijo. Luego le ofreció asiento, pero no me dejaba ver la cara mi mujer, dijo el joven, -me andaba dando la espalda y andaba trayendo los ojos tapados con el rebozo.
5. - ¿Chem mu ta vemngechiedu ta ta?, yewenkepenu may ta ta pi ñi rakiduam, pirki. Veymu umañaymi, pingi piam ti weche wentru. -Umañan, pepapeyu ta ta, pi piam ti weche wentru kay. Veymu piam -ükelaymi kollu' ${ }^{16}$ pingi. -Veymew epu rume rakiduamnagün, pipingi ${ }^{17}$, püchi pelkenagi ñi piwke, allwe chiñülnagi iñ longko, pirki.

5. - ¿Por qué hace (actúa) así? Quizá me tiene vergüenza, pensaba, decía. -Vas a alojar (aqui), le dijo al joven. -Voy a alojar, te he venido a ver, pues, dicen que dijo el joven. Luego le dijo: -Amarra el caballo. -Entonces lo pensé dos veces, decía, -sintió un poco de susto mi corazón, se me heló algo la cabeza, decía.
6. Veymew -Entuchillawan, pi piam ti weche wentru. - ¡Welu amutukelmi ke ka!, pirkeyu ti domo. -No, vemlaan, umañan ta ta, pirki. Amuy piam pemelu iñ kollu. Veymew vemngechilu vey veylay ñi rakiduam piam. -Entuchillawlaan, pi piam ti weche wentru, -elkünon ñi kollu veymungechi. Ükelkünoy piam vey ká wiñokonpay.

7. Veymew vemngechilu vey ta ká powi piam tayñi mülemom tayñi domo ka anüpoy. Veymew ká vemngechiki piam, oñonküli ti domo, meki piam ñi kuletun ke kütral mu. -Veymu vülüntukuy ngülliw ti domo vey kuletuy, pipingi ti weche wentru.

8. -Veymew entulpaanu kiñe rali mew tukulelenu ngülliw. ¡Ingülliwnge! pienu, pipingi. -Anükünolpaanu ngülliw; veymu madumtukun kütral, newe üykelay ti kütral, pipingi ti weche wentru. $-i$ Chem mu ta ta veli?, piki ñi rakiduam.
6. Entonces dijo el joven:-Voy a desensillar. -iPero no te vayas!, le dijo la mujer. - ¡No, no lo haré, voy a alojar (aqui), pues!, dijo. Fue a ver a su caballo, (pero), en vista de lo que ocurría, cambió de idea. -No voy a desensillar, dijo el joven, voy a dejar mi caballo ahí mismo. (Lo) dejó amarrado y volvió a entrar.

7. Entonces, así las cosas, llegó de nuevo donde estaba su mujer y se sentó ahí. Otra vez actuó así. (Le) daba la espalda la mujer, ocupada tostando piñones en el fuego.-Puso un puñado de piñones la mujer y (los) tostó, decía el joven.

Entonces puso en un plato piñones (y) me lo pasó. ¡Come piñones!, me dijo, decía. -Me vino a dejar piñones; entonces aticé el fuego, que apenas ardía, decía el joven. - ¿Por qué está así?, pensaba.

9. -Veymew nünütun ñi 9 9. -Entonces agarré mis ngülliw ñi ial. Veymu re kuyül piñones para comerlos: eran reke. -Veymu ula pütta weda como carbón. -Luego cambié kangi iñ rakiduam, pi piam ti mucho de parecer, decía weche wentru. $-\mathrm{No}$, re che el joven. - $\mathrm{iNo}$, no es gente no ta ta, pi piam. -Veymew (persona)!, dijo. -Estábamos veleyu, kintulaanu kidu. Inche los dos ahí. Ella no me miraba; kintuneviñ, pipingi ti weche yo la miraba fijamente, decía wentru.

yo la mirat joven. 
10. -Veymu vemngechi anüpüramün kintun, pürakintun. Pültrüli ñi kumüñ, itropüra kütral, pipingi. -Vey chilümnagi ñi angka ventre weda iñ llikan, pipingi. Pültrüli ti kumüñ.
10. -Entonces levanté la mirada hacia arriba, miré hacia arriba. Estaba colgado su cadáver $^{18}$ justo arriba del fuego, decía. -Me tiritó todo el cuerpo de puro miedo, decía. Estaba colgado el cadáver.
II. Veymew -Entuchillawpelan lamngen, piviñ, pipingi.Entuchillakawnge müten, pienu. -Umañayu tamu, welu yean nga tüvachi travia pienu, pipingi ti weche wentru. -Ya, yepaayu, pi piam, -kümelmen iñ chillankollu. To kültel-lanu ti püttapüra, pi piam.
II. Entonces le dije: - Creo que voy a desensillar, hermana. -Desensilla nomás me dijo. - Vamos a alojar aquí los dos, pero esta noche me vas a llevar, me dijo, decía el joven. -Está bien, te voy a llevar, dijo. -Voy a arreglar mi caballo ensillado. No me soltó la niña, dicen que decía.
12. -Veymew vemngechilu vey utratripan, welu oñonkiawi, pipingi. -Veymu tripalu ülngin mu inche wiñokintun, püchi pevemmaviñ ñi ange tayñi domo, pi piam. -Trololküli ñi nge, nielay nge, pipingi. Trololküli piam tayñi nge.
12. -Entonces me levanté y salí, pero ella andaba dando la espalda, decía. Cuando salí de la puerta, miré hacia atrás y le vi de repente un poco sus ojos a mi mujer, decía. -Estaban huecos sus ojos, no tenía ojos, decía. Dicen que estaban huecos sus ojos.
13. -Vey tripapan vey pepan ñi kollu, nürüvtun, pipingi. -Leventuan pi ñi rakiduam vey veymu powkintun tayñi domo, kintuneuyenu ülngin ruka mu. Chayno epe tripaleuyi, pi piam.

14. Veymu ñawlüy piam kiñe pütta llasu ti weche wentru. Nürüvtuy iñ kollu piam, entukünoy iñ llasu vey pürakolluvemüy piam, venteka tripay ñi wirav ti wentru travia. Amutuy piam. Venteka piam inaeyu ti püttapüra, vurüinaeyu. -Müt'ay epe dipoonu, pipingi. -Veymu kiñe llasu yenelu inche kay uvüykünolkaviñ iñ llasu, veymu püchiken iñetripaki püttapüra.
13. -Entonces salí y vine a ver a mi caballo, apreté la cincha, decía. -Voy a disparar ${ }^{19}$, pensé. Entonces miré a mi mujer; ya me había estado mirando fijamente desde la puerta de la casa. Ya casi había salido, dicen que decía.
14. Dicen que el joven andaba trayendo un lazo grande. Apretó la cincha de su caballo, sacó su lazo y de inmediato montó a caballo y salió en seguida galopando, en la noche. Se fue. Dicen que en seguida lo siguió la niña, le pisaba los talones ${ }^{20}$ -Luego, casi me alcanzó, decía. -Entonces, como yo llevaba un lazo, lo borneaba ${ }^{21}$. Ahí retrocedía un poco la niña.

15. -Velen amun, powün kiñe pütta leynga ${ }^{22} \mathrm{mu}$ vey rüngkünakümkünowpon iñ kollu mu ka venteka rüngküpüravemün ti lenga mu, pipingi. Ekotupüray piam, wechuñpoy. -Veymu powi ti domo, pürakintuialponu. Venteka ngütrümüy: -iKünapamün Tükarkiñ, künapange Chayankadi, Karü chumpiru!, pi piam ñi ngütrüm. -iKünapamün, katrülmopaan tüvachi koyam! $!^{23}$, pi ñi ngütrüm.

16. -Vey müchayno müten kuninkünkepi $\mathrm{kila}^{24}$, pu a moverse las quilas en la pewenentu, pipingi. -Veymu pinalería ${ }^{26}$, decía. -Entonces peviñ tripankepipay pu vi que empezaron a salir, uno wentru. Veymu ti Tütarkiñ detrás del otro, los hombres. El püttakamatripa peenu, pipingi. que mira para arriba me había Tükarkülen upay: - ¿Tie no visto desde lejos, decía. Pasó anchi? ${ }^{25}$, pirki. Veymu piam mirando hacia arriba. -iAquel akuy ti pu wentru. -iKatrülmon es!, dijo. Entonces llegaron los tüvachi koyam, nagüñmaviñ hombres. -¡Córtenme este tüvachi wentru!, pi piam ti árbol, voy a hacer bajar a este domo. Ka ke menkunii tayñi hombre!, decía la mujer. Dicen trilev engün piam tati pu que cada uno de los hombres wentru. llevaba al hombro su hacha ${ }^{27}$.

17. Vemngechilu vey ta katralu, wallkatrüngün piam. alrededor (del árbol). TocToktoküy piam iñ tokitun toc sonaban sus hachazos. engün. Veymew vemngechilu Entonces estuvo empujando vey altroaltrotumeki piam ti varias veces el Costilla rota. Chayankadi. Vey -Epe tranüy, -Casi cayó, decía. De nuevo piki piam. Káa elukingün piam. comenzaron (a cortar). Otra Müchayno ká altrotukameki vez empujaron. ¡Casi cayó,! piam engün. -¡Epe tranüy!, piki decían. Entonces se movía piam. Veymu piam nengumki el árbol de ese hombre. -Yo tayñi aliwen ta ti wentru. creía que se movía, decía. -Nengumkelu chukukeviñ, Tenía miedo el hombre.-¿Qué pipingi, vey piam llikaki ti voy a hacer?, decía. Otra vez wentru. - $i$ Chumkünoan an comenzaron (a dar hachazos). ta?, piki piam. Káa elukingün -Cortaban alrededor de mi piam -Wallkatrüñmakeenu iñ árbol, decía.

koyam engün, pipingi.

18. Veymu vemngechilu vey upay travia. Nopiñkünuwelay veymu piam willeñnakümi, willeñnakümelvi piam. Vey vemngechilu -iUtrey nay, mawi apuen!, piwingün, mawiñmaiñ. Veymu ti Tükarkiñ pürakintuki. -¡Müchay kallipe, müchay nagpaay ta ti!, piki piam. Káa eluki piam tayñi tokitual engün. Káa altroaltrotuki, nengumkingün pütta koyam.
18. Así pasó la noche. No aguantó más ahí y tuvo ganas de orinar; dicen que los orinó. Entonces se dijeron unos a otros. - ¡Caramba, está Iloviendo, amigos! -Nos llovió. El que mira hacia arriba miraba hacia lo alto. - $i \mathrm{Va}$ a ver nomás, luego va a caer!, decía. De nuevo comenzaron a dar hachazos. Otra vez empujaban (y) movían el árbol grande. 
19. -Veymew vemngechilu inche chem weda llikaken vemngechiel pütta koyam mu che. Veymu káa küpalkawün, káa leykümnakümkünolviñ. Veymew vemngechilu vey ¡metu pirenüy!, ká piwingün. Mekingün.

20. Veymu vemngechilu vey velen kiñe pun veli piam veymew. Meki piam iñ katrün engün. Veymew upatraviarki, epewün ula vey veymu piam dunguy killkill. -Killkill, killkill, killkill, pipay piam killkill.Veymu vemngechilu vey -¡Utrey nay!, piwingün, chukilkonmay nay, wünmaiñ, amutuiñ apuen, pi piam. -Vey llikalkawüy ti pu wentru, pipingi. $-\mathrm{Na}$ weda llikarki killkill engün, pipingi. Veymu vemngechilu vey kom ka ke udachipatuy. Ñivnagtuingün vey ti püttapüra kavey.-Amutuingün, pipingi.

21. -Velen lingavüy wün. Livlu wün ngetulay chem ume veymu vey kollu amukalay kay, veymungelli ñawi, pipingi. Veymew vemngechilu vey nagpatuy piam. Nagpatulu vey ta kintulpatuy piam tayñi katrüñmangeken tayñi pütta leynga. -Chumkülelay ume, pipingi. -T'üm no ume, pünon ume ngelay.Vey tayñi nagümpal vey mülekay vey kom. Veymew vemngechilu vey ta küpatuy piam nga tayñi kollu mew.

22. -Veymu ti Tükarkiñ vey ta ti pültrükünowchi wentrurke ñi inamongen, pipingi, vey ti Chayankadi vey ta ti chingarel ta lalu. Ta ti Karü chumpiru vey ta ti karülalu vey ñi inamongenürke, pipingi. Vemngechi piam ngütramkatuy ti weche wentru powtulu in ruka mew. -Vemngechi upan, pipingi. Ventepoy ti perimontun ngütram.
19. -Entonces yo tenía mucho miedo por lo que hacían los hombres en el árbol grande. Luego me dieron también ganas de dar del cuerpo, y otra vez les dejé caer. Entonces, otra vez se dijeron unos a otros: -¡Está nevando! Seguían ocupados (dando hachazos).

20. Estuvo una noche así ahí. Ellos seguían ocupados cortando. Entonces pasó la noche $y$ al alba gritó el quilquil ${ }^{28}$. -quillquill, quillquill, quillquill, gritó el quilquil. -¡Caramba!, se dijeron unos a otros, anda correteando, pues, nos amaneció, vámonos, amigos; (eso) dicen que dijeron. Les dio miedo a los hombres, decía. -Le tenían mucho miedo al quilquil, decía. Entonces, cada uno se apartó (del árbol). Se quedaron callados y la niña también. -Se fueron, decía.

2I. -Así, aclaró la aurora. Al blanquear el alba, no había nada ahí. El caballo no se había ido; andaba ahí mismo, decía. Entonces se bajó y vino a mirar donde habían estado cortando su lenga grande. -No le había pasado ni una cosa, decía. No había nada, ni rastro. Lo que yo les había tirado desde arriba, todo estaba todavía ahí. Así entonces, volvió donde estaba su caballo.

22. -Entonces, El que mira para arriba es el alma de un hombre que se ahorca, decía; -El costilla rota es el alma del que muere apuñalado ${ }^{29}$; El Sombrero verde es el alma del que muere de repente' ${ }^{30}$, decía. Dicen que así conversó el joven cuando llegó a su casa. -Eso me pasó, decía. Hasta ahí llega la conversa sobre una 'visión'.

\section{Los kovkeche ${ }^{31}$}

(Narrado por Ramón Naupa Epuñán, el 24.02. 1988)

Antes vivía gente debajo de la tierra, según contaban. Una vez un hombre encontró un hoyo en la tierra y, al mirar hacia abajo, vio que estaba iluminado; entonces bajó y llegó donde estaban (vivían) los "hombres del pan", los cuales eran muchos y estaban en guerra con los jotes. Estos se los comían. Como el hombre llevaba un sable, cuando llegó lo quisieron mucho, y le pidieron que los ayudara a guerrear. Al llegar los jotes, los golpeó con su sable, dejándolos amontonados. Por eso los "hombres del pan" lo quisieron mucho y le dieron una niña para que se casara. Los kovkeche eran pequeños, pero tenían las espaldas anchas. Cuando esperaba familia su mujer, se murió. Entonces, como el hombre era tan diferente, sintió pena y decidió volver a su tierra. Le pidieron que se quedara -dándole otra niña-, pero no quiso. Como recordaba por donde había entrado, pudo hacerlo. Ya de regresó conversó sobre la gente que vive debajo de la tierra.

\begin{tabular}{|l|l|}
\hline $\begin{array}{l}\text { 0. Tüva perimontun ngütram, } \\
\text { ngütramkaki tayñi ñuke em. }\end{array}$ & $\begin{array}{l}\text { 0. Esta es una conversación } \\
\text { sobre una “visión” (que) decía } \\
\text { mi finada madre. }\end{array}$
\end{tabular}

I. -Kuyvi vey ta minche mapu káa mülerki ta che, piki, eypiki tayñi ngütram tayñi püttake che em, piki.
I. -Dicen que antiguamente vivía gente también debajo de la tierra, decía. -Eso conversaban mis finados mayores, decía.
2. -Veymew kiñe wentru legürki ta ti trolol mapu mew, piki. -Vey nagkintulu vey ta ayomlerki, piki tayñi ngütram. -Veymu ayiwmarki ti wentru, piki. -Vey nagürki nga, konürki pu mapu. -Mülerki ta nagkintu, piki.

3. -Vey powürki tayñi mülemom tati pu kovkeche, piki. -Kovkeche pingi, piki. Veymew powlu ventelerki che. -Metu weychay ti pu che, piki iñ ngütram engün. Meki piam weychan.-Vey tati pu kovkeche vey ta weychakerkeyu ta kotté piki. Vey ti kotté ilotukerkeyu engün.
2. -Entonces un hombre encontró un hoyo en la tierra, decía. -Cuando miró hacia abajo, estaba claro, conversaba. -Entonces se alegró el hombre, decía. Bajó, pues, (y) entró en la tierra. -Había una bajada, decía.
3. -Entonces llegó adonde vivían los 'hombres del pan', decía. Se llaman hombres del pan, decía. Dicen que cuando llegó había mucha gente. -La gente está guerreando, conversaban. Estaban en guerra. -Esa 'gente del pan' guerreaba con los jotes, decía. Los jotes se los comían ${ }^{32}$. 
4. -Veymew powlu kidu pütta wentru kay nga ti vey yerki sable, piki. -Veymew chem weda ayingen, pikerki in ngütram. Veymew -Müleaymi tamu, ingkamoiñ ta tüvachi weychan mew pingen, pi piam tayñi ngütram ti wentru. Vey eluwi piam.
4. -Cuando llegó allá, como era un hombre grande, llevaba un sable. -Por eso me quisieron muchísimo, conversaba. -Te quedarás aquí, nos vas a ayudar en esta guerra me dijeron, conversaba el hombre. Dicen que se alistó.
5. Veymew müchay müten ká 5 . Entonces, luego nomás akuy ti pu kona weichaadu. llegaron otra vez los -Veymu pülpüli may pu kotte, piki piam iñ ngütram. Veymew nentupay iñ sable.-Müttangeviñ engün, vülümkakünon kotte, piki piam. Veymu piam chem weda ayingi. mocetones que iban a pelear.Volaban juntos los jotes, conversaba. Entonces sacó su sable. -Les di golpes, los dejé amontonados a los jotes, decía. Por eso, dicen que lo quisieron muchísimo.

6. Veymu vemngechilu piam elungi kiñe malen tayñi ngünayetoal. Vey -Müleaymi tamu, kurengeaymi, pingi piam. Vey ngünaetuy piam.

7. Vemngen vey piam ta ti pu kovkeche ta püttiki nga. Vey '-Inche rüv pütta umeleken ti pu che, piki piam ñi ngütram ti wentru.Vey ti püttike che piam ta lavtrake püchike wentru müli, welu rüv wancheke rupay piam tayñi vurü nga, kakülkaküli piam ta ti püchike che vey ta ti kovkeche', piki iñ nuke em.

8. Veymew ngünayetulu kay nga ti vey ta dehpueh piam niechepolu tayñi kure vey piam lay nga, latuy ñi kure. Vey kangechi che kay nga ti veymu piam ká duamüy ta ti wentru. Weñangküy piam. -Ká duamün, pipingi. -Doy kümi amuton ñi mapu mu, pi piam, kimnekalu chew ñi konmom kay nga ti.
6. Así, pues, le dieron una niña para que se casara. -Vivirás aquí, te casarás, le dijeron. Dicen que se casó.

7. Así, dicen que los 'hombres del pan' eran chicos. -Yo sobrepasaba mucho a la gente, conversaba el hombre. -Los hombres chicos eran petizos, pero tenían la espalda así de ancha; eran anchos hacia los lados esos hombres chicos, los 'hombres del pan', según dicen, decía mi finada madre.

8. Después de casarse, cuando después su mujer iba a tener familia, se murió. Se murió su mujer. Entonces, como era una persona diferente (de los hombres del pan), cambió de idea el hombre. Dicen que decía. -Mejor me voy a mi tierra, dicen que dijo, como todavía recordaba por donde había entrado. le dio pena. -Cambié de idea,
9. -¡Ká müleymi!, pingi 9 9. -iQuédate más (tiempo)!, piam. Piwelay. Ká elungevüy le dijeron. No quiso. Dicen piam ká malen. Piwelay nga. que le dieron otra niña. -¡Amuton!, pi piam. Vey piam No quiso. -jMe voy!, dijo. trekakünowtuy chew tayñi Entonces caminó hacia donde konpomom piam, kimnekalu había entrado, pues todavía piam kay. Veymu piam ká recordaba. Entonces salió tripapatuy. Akutuy. hacia acá. Dicen que volvió (a su tierra).

10. -Vey akutulu vey piam 10.-Cuando volvió, dicen que ta entupatuy tayñi ngütram conversó sobre la gente que vey tayñi ká mülen ta che vive también debajo de la minchemapu, piki iñ ñuke em. tierra, decía mi finada madre.

\section{Perimontun del suegro del cheruve (Narrado por Basilio Porteño Paine "Wenumañ"33 el 9.04.1990).}

Dicen que, una vez, en Cauñicú no había mantención (alimento) ${ }^{34}$. En esa ocasión la gente comía pasto, con el cual vivía, sobre todo cuando no había piñones. Entonces un hombre tuvo una 'visión'. "La piedra que martillea" se llamaba el lugar en la comunidad, porque "martillaba" cuando iba a llover. Vivía allí un matrimonio -un viejo y una vieja- que tenían una hija. Antes las hijas tenían mucho valor. Una vez se echó a perder el tiempo y había truenos. Entonces la niña salió a buscar piñones, pero se perdió; no llegó a la casa. La llamaron por todos lados, pero no llegó en toda la noche. No durmieron los dos pobres viejos. Al otro día apareció ahí donde había desaparecido, se le apareció a su madre. Le dijo a esta que se había casado, que la habían venido a buscar cuando hubo tormenta. La habló de lejos a su madre, pues se había vuelto loba (arisca). Entonces le indicó a su madre donde había dollümko (piñón remojado). Luego de decirle donde había, desapareció. Buscó piñones (y encontró).

Otra vez, cuando hubo tormenta, vino a buscar a su padre. Entonces este perdió el sentido. Lo recuperó en un lugar llamado "Piedra amarilla". Ahí había un viejo y una vieja. Estos le preguntaron si venía a ver a su hija. Respondió que sí. La vieja le informó que su hija había venido a vivir ahí, y que su hijo -el marido- andaba cazando por todas partes. El viejo le dijo también que su hijo andaba cazando, que era muy mañoso, y que luego volvería. Le aconsejó que, cuando su hijo le hablara, solo le contestara a la tercera vez; así no le ocurriría nada. 
Cuando terminó de comer, llegó el hijo. Retumbó la montaña. Él llevaba hartas cabezas (humanas) vivas. El hombre estaba cateando y se fijó que no se atragantaban al comer las cabezas. El hombre (de la montaña) percibió el mal olor del humano. El suegro solo respondió a su saludo a la tercera vez. Luego, conversaron amigablemente. Entonces el yerno lo invitó a participar en un juego de chueca. Fue a ayudarle en el juego de chueca. De nuevo perdió el sentido. Jugaron en una vega, donde se juntó mucha gente. Ganaron en el juego. Recibió plata de las apuestas, y comió también cabezas humanas. Regresó y nuevamente perdió el sentido. Volvieron a vivir bien, y ya no les faltaron los piñones.

\begin{tabular}{|c|c|}
\hline $\begin{array}{l}\text { I. -Kiñe rupachi, piki tayñi } \\
\text { abuelo em tamu mülekelu, } \\
\text { ngelay ta mongewe, piki. } \\
\text { Tüvachi kachu ta yii ta che, } \\
\text { pi, kiñe kachu müli mawida } \\
\text { mu, 'wentray' pingi. Veymu } \\
\text { ta mongeki ta che, avülngeki } \\
\text { piam vey dehpueh piam } \\
\text { vemngechi ngütrarngeki ka } \\
\text { püttake trükokünongeki vey } \\
\text { piam iki che, avün mu. Vey } \\
\text { tukulpanen. Ngekenolu kay } \\
\text { piam vey kom antü trekayawki. } \\
\text { Kiñeke pekelay kiñe ngülliw no } \\
\text { ume vey. Vey vemngechikelu } \\
\text { engün tüva Kawñiku piam } \\
\text { perimontuki kiñe wentru, } \\
\text { Kawñiku pewen mu. }\end{array}$ & $\begin{array}{l}\text { I. -Una vez -decía mi finado } \\
\text { abuelo que vivía aquí- no } \\
\text { había mantención. Este pasto } \\
\text { comía la gente, un pasto que } \\
\text { hay en la montaña que se } \\
\text { llama 'huentrai'35, decía. Con } \\
\text { eso vivía la gente; lo apretaban } \\
\text { y lo hacían pelotas grandes y } \\
\text { lo comía la gente, cocido. Me } \\
\text { acuerdo. Cuando no había, } \\
\text { caminaban todo el día; a veces } \\
\text { no hallaban ningún piñón. } \\
\text { Cuando andaban así, dicen } \\
\text { que aquí, en la pinalería de } \\
\text { Cauñicú, un hombre tuvo una } \\
\text { 'visión'. }\end{array}$ \\
\hline
\end{tabular}

2. Traytraykura pingeki kuyvi vey tayñi kovke, veymu mawal mu piam traytray kümengeki traytray traytray traytay. Mawalu ta ti,'seña', piki püttake wentru em mülekepolu. Pekenolu iñ ial engün vey kiñe kusé ka kiñe pütta wentru, nieki piam kiñe koñi ${ }^{36}$ ti kusé, püttapüra koñi. Kuyvi piam 'sakin' pikelayngün anchi. 'Sakin' piki ñi püñeñ engün nga. Niele kiñe domoche veymu piam ngillañmawki ñi püñeñ engün kuyvi. Domoche piam na vali kuyvi, kiñe kollu, epu kollu ngillañngeki kiñe domoche pikingün tayñi ilotual engün. 'Trantuy' pingi ti kurengelu nga.
2. La piedra Traytray se llamaba antes donde está nuestro pan (el piñón). Cuando va a llover martillea: traitrai, traitrai, traitrai. -Va a llover, es seña, decían los antiguos que vivían allá. Cuando no hallaban comida, (había) una vieja y un viejo; la vieja tenía una hija, una niña. Antes les decían 'sakin' ${ }^{37}$ a sus hijas. Si se tenía una mujer, entonces se vendían las hijas, antes. Una mujer valía mucho antes. Por un caballo, dos caballos se vendía una mujer, según dicen, para tener comida. 'Trantuy' se llamaba a la que se iba a casar.

3. Veymu piam kiñe rupachi vamngechi werakünowi, tralkanüy, tripay piam ti püttapüra. Tripaki piam siempre kintungülliwalu kay. Tralkanüy piam. -Tralkanüy, pi tayñi abuelo em. Veymu pütrüñma newentuy piam tralkan. Dewma tarde no ve vey ñamuy piam ti püttapüra, ñamuy, akulay. Traviay. Ngütrümngi, ngütrümngi, kañpüle ka ngütrümngi. No. Velen upay travia, umawtulay piam ti epu ellake vütta.

4. Wünpüle pelayngu pünon ume. Ká wünpüle ula ka pevaluy tayñi amumom püle, veychi püle piam ka upalu, veymu ula pevaluy iñ ñuke em ti domoche, püttapüra. $-i$ Chew an ta miawpetuymi? pi piam. Kuyvi ta piam üytukelay che üy $\mathrm{mu}$ ta che Ile.'Püllaw' ${ }^{38}$ pi tayñi koñi ta pu kusé vey ká adkünowi ta che üy mu, üytungelay. Vey piam ngütramkayu tayñi koñi tati kusé. -Tüva inche ta vüttangen tata, wiya u epuemom nga veychi pütta tralkan, pi nga, veychi ta yengepan, pi piam ñi ñuke tati püttapüra. ¡Lobowtuy piam nga ! Iñekontuvalnolu pi piam, püchi al-lümapu dungulvi piam.

5. Vey -¿Pekelaymün mün ial? Ña püchi müli tamn ial, veymu ta müli ta dollümko ${ }^{40}$, veymu ta pelelmeve, veymu ta müli ta dollümko, pingi veychi. Veymu ta vencheli ta ngülliw. -Küpamongelmün eypiayu chew tayñi mülen. Tam ruka lle tayñi mülemom püchi pulomtu, veymu ta müli.Veymu kintukaymün müten, üremküli ko mu, pi piam tayñi nuke ti püttapüra. Petu ñi eypin ñamtuy, amutuy. Vey kintuy nga, ngünün na werali kay. Chem trüglay ngüñün lle, igual tachi wiwün nga. Wiwüy che, pelay ko, ¿chumay may? Trekakünowi nga kintolu vey ula velewi.
3. Entonces dicen que una vez así se puso malo el tiempo, hubo truenos (y) salió la niña; salía siempre a buscar piñones. Había truenos. -Dicen que había truenos, decía mi finado abuelo. Dicen que entonces tronaba muy fuerte. Ya era tarde y la niña se perdió; se perdió, no llegó. Anocheció. La llamaron, la llamaron, la llamaron por todos lados. No. Así pasó (transcurrió) la noche, dicen que no durmieron los dos pobres viejos.

\begin{abstract}
4. A la mañana siguiente no hallaron ni rastro. Después, al otro día se apareció por ahí donde se había ido, por ahí volvió a pasar, ahí se le apareció a su madre la mujer, la niña. -'¿Dónde andabas?', dijo (la madre). Dicen que antes a la gente no se la llamaba por su nombre. 'Tía' les decían a sus hijas las viejas. Era de otra manera la gente en cuanto a nombre; no tenía nombre. Entonces le conversó a la vieja su hija: -'¡Ahora yo estoy casada! Ayer, o antes de ayer, cuando 'tormenteó' tanto, me vinieron a buscar', dijo la niña a su madre. ¡Se volvió loba! ${ }^{39}$. Como no se podía acercar, dicen que le habló de lejitos.
\end{abstract}

5. - ¿No hallan su comida? Muy cerca está su comida, ahí hay 'piñón húmedo', anda a verlo, ahí hay 'piñón húmedo' le dijo entonces. Ahí hay hartos piñones. -Si quieren vivir, te diré donde hay. De donde está tu casa, un poco hacia el bajo, ahí hay. Ahí busquen nomás, están remojados en agua (los piñones), dijo la niña a su madre. Mientras decía eso, desapareció, se fue. Entonces buscó (la madre), pues había mucha hambre. Nada es igual al hambre, lo mismo la sed. Si la gente tiene sed y no halla agua, ¿qué va a hacer, pues? Se puso a caminar para buscar. Después quedó conforme 
6. Veymu ká vemngechi tralkanüy piam, yepay piam tayñi chaw ta ti domoche. -Ventekim(v)emün, pi piam ti vütta ka venteñma piam ñamuy. Vey tüvichi Blanko mawida pengengi tüva, Chodwekurawe pingelu pingeki ta ti che üy mu, veymu kimkonpon, mülepon, pi piam ti vütta wentru. Veymu kiñe kusé müli ka kiñe pütta wentru.

7. Vey -iAkuymi, pepapimi tam ñawe am? pingen, $p i$ ta ti pütta wentru. -Pepapen. -Tüva mu mülepay tami ñawe. Inche tayñi koñi villpüle ta upaki, nüvakelu, pienu ti kusé, pi piam. Vey velewi nga tayñi ñawe mu powlu kay nga ti. Veymu eypieyu pütta wentru: -Inche nien kiñe votüm, petu nüvay, mütte weñañmangi, müchay akutolu, veymu dungulel mu, dungulaaymi, ñiküvküleymi, epuchi dungulel mu, no; külachi dungulel mu ula dungulavimi, veymu chumlaaymi, pieyu piam ti pütta wentru.

8.Yavutulngi nga. Upan yavutulu lululpotuy piam, powtuy piam, peñi [GS.]. Pütrün longko piam powlüy, mongenchi longko, vamtukukünopotuy piam. -¡Luuul! pi ti mawida, pi piam ti pütta wentru. Inaduamlelu kidu kay ia ti -veymu mürilayngün, pi piam. -Chumkülen ta umelu ti pu longko, pituki.
6. Entonces, otra vez que hubo tormenta, dicen que vino a buscar a su padre esa mujer. -Perdí de repente el sentido, dijo el viejo, y se perdió por un tiempo. -(En) esa Montaña Blanca que se ve ahora, que se llama en mapuche Chodwekurawe (La piedra amarilla), ahí recobré el sentido, ahí llegué, decía el viejo. Ahí vivían una vieja y un viejo.

7. -iLlegaste, viniste a ver a tu hija?, me dijeron, dijo el hombre viejo. -(La) vine a ver. -Aquí vino a vivir tu hija. Mi hijo pasa (anda) por todas partes cazando, me dijo la vieja, decía. Quedó tranquilo porque llegó donde su hija. Entonces le dijo el viejo: -Yo tengo un hijo que anda cazando, es muy mañoso; luego va a llegar. Cuando te hable, no hables, quédate callado; a la segunda vez que hable, no; después de la tercera vez que te hable, háblale, entonces no te va a pasar nada, dicen que le dijo el viejo.

8. Le dieron de comer. Después de comer, retumbó (la montaña), llegó, hermano (GS.). Andaba trayendo hartas cabezas, cabezas vivas ${ }^{41}$. Las fue a dejar (ahí). -iLuuul! dijo (sonó) la montaña, dijo el viejo. Como él estaba cateando, no se atoraron, dicen que decía. -Quizá cómo pasaron las cabezas (por el gaznate), decía.
9. Vey dungupotuy: -¿Chem 9. Entonces habló allá: -¿Qué anta mülepay? Pütrün na cosa vino a estar aquí (que) weda nümüy. ¿Marimari, huele muy mal? ¡Buenos marimari, marimari pipelanam? días, buenos días, buenos Vewla: -Marimari. -jMm, días he dicho!. Recién ahora: dungukarketulaymi nga!, -Buenos días. -iMm, así que pi piam ñi ngenchedkuy. no hablaste!, dijo su yerno. Ngütramkawingu, itrovill Conversaron de todo los dos. ngütram. Veymu: -Tüva Entonces: -Ahora voy a jugar palimelu inche, kayñelngen, a la chueca, me desafiaron a palimelu inche. ¿Chumlimi jugar a la chueca. ¿Cómo te chedkuy, ingkamelaan palin hallas, suegro, para ayudarme mu? ¿Palikelaymi am?. -Paliken. a jugar a la chueca? ¿Juegas a -Vey ta ti, ingkamean palin mu. la chueca?. -(Si) acostumbro ¿Chew chi te?

jugar a la chueca. -Eso es, me vas a ir a ayudar a jugar a la chueca. ¿Dónde será?

10. Amuy piam pütta wentru ingkamelu iñ chedkuy palin mu. Vey: -Ventekim(v)emün, piki ti vütta wentru, -mülepon kiñe lelvun mu. Pütta trawli che vey ta kudelurkingün, pi piam ti vütta wentru. -Longko laalu no ve püchilewelu iñ mongen vey nga ti llovtuiawlvingün. Vey palingün. -Düngüll mu tukulelenu iñ chedkuy, pi piam ti pütta wentru. Wewmiiñ, pi piam -wewmiiñ. -Eyewngelli nga elungiiñ kullin, tayñi ran (ran piki ta che kuyvi tayñi positan nga ñi chemkün kullin, plata ${ }^{42}$ ) vey. Vey -veymu ta yin kay, pi piam ti pütta wentru. -Elungen, pi piam, -vamtukukünolenu iñ chedkuy. Chem magia chemchi teni (müten nii), ülakünovemüy tayñi wün, umeuyi ti longkoche, pi piam.
10. Dicen que fue el viejo a ayudar a su yerno en la chueca. -Perdí de repente el sentido, decía el viejo. -Llegué a una vega. Se juntó harta gente, luego apostaron, decía el viejo. Como eran cabezas de muertos a las que les quedaba poca vida, lo andaban aguaitando. Jugaron a la chueca. -Me puso de delantero mi yerno, decía el viejo. -Ganamos, ganamos, dijo. -Ahí mismo nos dieron plata, nuestra apuesta (ran llamaban los antiguos a lo que se deposita, cualquier cosa, plata). dio mi yerno, decía el viejo. -Quizá sería solo magia, abrió de repente su boca (y) ya se tragó las cabezas, dicen que decía. --Entonces comí también, me 
II.-Ká küpatun ka vemngechin, ventekim(v)emün, elpatenu ñi ñawe chew tayñi ñammom, veymu elpatenu iñ ñawe, $p i$ piam ti pütta wentru. -Vey ta küme mongengetun nga. Chayno elupal ta mongewe kay ia ti, entunengi müten, avlay. Inche miawyen vey tayñi eypingemom re rakiduammakeviñ ti menuko ${ }^{43}$, kiñe menuko llechi müli pewen mu, ventren che ta powki kuyvi mu. Tüva velewelay che, epu, küla rukali, puehtu, melichi. Tüvapülepa ka müli pekelayngün ama lovpewen mu. ¡Vemngechi ngütramkawi ñi pütta abuelo em, anü!
II. -Me volví y otra vez me pasó que de repente perdí el sentido; me vino a dejar mi hija donde se perdió, ahí me vino a dejar mi hija, decía el viejo. -Volví a vivir bien. Como ya les dieron comida, sacaron nomás (y) no se acabó (el piñón). Yo iba antes donde me dijeron. Solo pensaba en el 'menuco'. Había un 'menuco' en la pinalería. Mucha gente llegaba allá antes. Ahora ya no hay gente; hay dos, tres o quizá cuatro 'puestos' ${ }^{\prime 4}$. Por este lado también había, dicen, en la pinalería. ¡Así conversaba mi finado abuelo, amigo!

\begin{tabular}{|c|c|}
\hline $\begin{array}{l}\text { I2. -Ka antü mongelelmün, } \\
\text { niepolmün pu püñeñ ká veychi } \\
\text { ngütram elovimün, pikevüy } \\
\text { em. Vemngechi rakiduamün, } \\
\text { peñi, veymu mopütuken tayñi } \\
\text { mülen ta wekuvü ta mawida } \\
\text { mu chengen mawida ngen- } \\
\text { pewen. Vey pewen vüchá } \\
\text { pipingi, vey pewen kusé pingi } \\
\text { tati ulkelu mongewe. Vey am } \\
\text { ta ngillatukeviñ inchiñ, pewen } \\
\text { mu powüiñ. Kiñeke tichi } \\
\text { mopütulelu veychi dungu tuy } \\
\text { ngülliw, chavidvaluy, püntevüy, } \\
\text { ngillatuy. Vemngechikevüy ta } \\
\text { kuyvike che, vemngechikevüy. } \\
\text { Inche mopütuken, peñi. }\end{array}$ & $\begin{array}{l}\text { 12. Otro día, si viven, si tienen } \\
\text { hijos, denles también esta } \\
\text { conversa, solía decir antes. } \\
\text { Así pienso, hermano, por } \\
\text { eso creo que hay wekuvü }{ }^{45} \\
\text { en la montaña, dueño de la } \\
\text { montaña, de la pinalería. Se } \\
\text { llama Anciano de los pinos- } \\
\text { Anciana de los pinos, repetía, } \\
\text { que dan mantención. Por eso } \\
\text { nosotros le hacemos rogativa, } \\
\text { llegamos hasta la pinalería; } \\
\text { algunos que creen en esto, } \\
\text { agarran piñones, mandan } \\
\text { a hacer chavid }{ }^{46} \text {, hacen } \\
\text { püntevün }{ }^{47} \text {, ruegan. Así hacían } \\
\text { los antiguos, así lo hacían. Yo } \\
\text { creo (en eso), hermano. }\end{array}$ \\
\hline
\end{tabular}

\section{Perimontun del hombre-serpiente}

\section{(Narrado por Felicinda Paine Queupil "Llovtuy"48, el 19.02.1989)}

Una niña solía ir a buscar agua a una vertiente. Un día, cuando iba a buscar agua, vio que ahí había una culebra. Ella le pegó con una piedra en la cabeza. Entonces la culebra arrancó y se escondió en una mata de quila. Otro día, cuando fue temprano a buscar agua, estaba sentado junto a la vertiente un joven. Estaba aguaitando (espiando) a la joven. Hablaron y, después, se casaron. Cuando pernoctaban, al alba, el hombre le pidió a la niña que le buscara piojos, para lo cual puso la cabeza sobre sus rodillas. Entonces ella vio que él tenía rota la cabeza. Al preguntarle

quien le había pegado, el joven le contestó que había sido ella quien lo golpeó con una piedra. En seguida el hombre se volvió culebra (y huyó). La niña tenía mucho miedo. Quedó embarazada y, cuando dio a luz, solo fueron culebras. Estas no terminaban de salir. Por esa causa la niña murió.

Dicen que antes las niñas tenían muchas "visiones". A ellas se les aconsejaba que, si ocurría con culebras, no las dejaran a medio morir, sino bien muertas. Si no las mataban, les llevaban el alma a las personas.

I. Eypiki tayñi nanüng ${ }^{49} \mathrm{em}$ vey ta kiñe püttapüra amuy moll komeki piam kiñe vertienteko müleki, püchaallütripali iñ ruka eypirki vey müli kiñe mancha kila ka ñire ${ }^{50}$. Veymu umeki ti püttapüra. Kidu müten komeki piam.
I. Decía mi finada suegra que una niña siempre iba a buscar agua (donde) había una vertiente. Estaba muy lejos su casa y había una mancha de quilas y ñirres. Por ahí pasaba la niña. Dicen que ella nomás buscaba agua.
2. Kiñe antü piam pepoy kiñe vilu komekelu. Kiñe vilu müli veychi nga, ina ko. Vey ulelerkevi ti vilu kiñe kura mu, ütrüvturkevi kiñe kura mu. -Longko mu küllirkevi, piki iñ nanüng em. -Longko mu küllivilu ti vilu, leventuwi nga vey ká konpotuy kiñe mata kila mu, piki. Konpoturki veymu.
2. Un día, cuando iba a buscar agua, dicen que vio a una culebra. Había una culebra ahí, junto al agua. Entonces le pegó a la culebra con una piedra. Dicen que le tiró con una piedra. -Le acertó en la cabeza, decía mi finada suegra. -Después que le acertó en la cabeza, disparó (arrancó) la culebra y se metió en una mata de quilas, decía. Entró ahí.

3. Vey dehpueh ká amurki vey kidu müten komekelu kay vey wünpüle ká amurki komelu vey kiñe weche wentru pepoturki anülelu ina ko. Llovtunengeturki ti püttapüra veymu dungulngerki, dungulürkeyu ti weche wentru. Vey kureyeteyu, kureyewingu.
4. Vey dehpueh umañelngerki ti püttapüra, umañentungerki piam. Vey wünpüle veymu eypirkeyu ti weche wentru. -.¿Chemmu kintulaan tün?, pirki. Vey wente ñi luku ti püttapüra tranakünowürki. -Kintulen tün ka, na ünayi iñ longko, pirkevi ti püttapüra.
3. Después, de nuevo fue a buscar agua. Como solo ella iba a buscar agua, al alba fue otra vez; entonces, vio a un joven sentado junto al agua. Estaba aguaitando a la niña. Entonces le habló el joven. Luego se casó con ella, se casaron ellos dos.
4. Después dicen que durmió con la niña. Entonces, al alba, me buscas piojos?, y se puso sobre las rodillas de la niña. -¡Búscame piojos, pues, me pica mucho la cabeza!, le dijo a la niña. le dijo el joven: - ¿Por qué no 


\begin{tabular}{|c|c|}
\hline $\begin{array}{l}\text { 5. Vey püttapüra nüñmarkevi } \\
\text { longko ti wechewentru, veymu } \\
\text { peñmarkevi iñ wedon, piam, } \\
\text { wedolelu iñ longko. Veymu } \\
\text { eypirkevi -iChumüymi am, } \\
\text { wedolimi?, ¿ñi anta uleleymu?, } \\
\text { pirkevi ti püttapüra. Veymu } \\
\text { eypirki ti weche wentru: } \\
\text {-iBaa, kimtulaymi eymi nga } \\
\text { ulelürkelaan nga longko mu, } \\
\text { küllien, ütrüvten kiñe kura mu } \\
\text { nga! }\end{array}$ & $\begin{array}{l}\text { 5. La niña le agarró la cabeza } \\
\text { al joven, entonces le vio que } \\
\text { tenía la cabeza rota. Entonces } \\
\text { le dijo: -¿Qué te pasó, pues? } \\
\text { Tienes rota la cabeza. ¿Quien } \\
\text { te pegó?, le dijo la niña. } \\
\text { Entonces dijo el joven: -Bah, } \\
\text { ¡no recuerdas que tu me } \\
\text { pegaste en la cabeza!; ¡me } \\
\text { acertaste con una piedra que } \\
\text { me tiraste, pues! }\end{array}$ \\
\hline $\begin{array}{l}\text { 6. -Vey dehpueh viluwtuy } \\
\text { ti wentru, piki, -viluwtuy. } \\
\text { Vey ti püttapüra piam pütta } \\
\text { llikatuy. Vey dehpueh motrüy } \\
\text { ti püttapüra, niecherki piam. } \\
\text { Vey powlu iñ tiempo niepoy } \\
\text { koñi, jre vilu piam nentutuy, } \\
\text { re vilu! Avlay ñi tripan ñi vilu. } \\
\text { Pelay piam ti püttapüra. -Velen } \\
\text { larupoy, latuy ti pütta-püra } \\
\text { vente nga iñ nietun vilu, veypiki } \\
\text { ñi nanüng em. }\end{array}$ & $\begin{array}{l}\text { 6. -Después se volvió culebra } \\
\text { el hombre, decía, -se volvió } \\
\text { culebra. Dicen que la niña } \\
\text { tenía mucho miedo. Después } \\
\text { engordó la niña; estaba } \\
\text { embarazada. Cuando llegó su } \\
\text { tiempo (de dar a luz) idicen } \\
\text { que tuvo puras culebras, puras } \\
\text { culebras! No terminaban } \\
\text { de salir sus culebras. No las } \\
\text { vio la niña. -Así, se debilitó } \\
\text { (y) se murió la niña, porque } \\
\text { tuvo tantas culebras, decía mi } \\
\text { finada suegra. }\end{array}$ \\
\hline
\end{tabular}

\begin{tabular}{|c|c|}
\hline $\begin{array}{l}\text { 7. -Veymu kuyvi mütte } \\
\text { perimontukevüy ta pu malen, } \\
\text { kuyvi mu. Mütte vilu mu ta } \\
\text { perimontuki ta püttakepüra, } \\
\text { piki iñ nanüng em. Veymu } \\
\text { ta eypikevi ti püttakepüra: } \\
\text {-Chemkün mu perimon } \\
\text { vilu, ütrüvtukelavimün, } \\
\text { lamngümavilmün, küme } \\
\text { lamngümkevimün, piki nga. } \\
\text {-Ella mongelkünokelavimün, } \\
\text { piki, porke yeñmangeki tayñi } \\
\text { pülli ta che, piki tayñi nanüng } \\
\text { em.. -Kom ta eypikevüy tayñi } \\
\text { pu kuku, piki iñ nanüng em. }\end{array}$ & $\begin{array}{l}\text { 7. - Antes 'perimontucaban'5l } \\
\text { mucho las niñas, antes. } \\
\text { Perimontucaban mucho con } \\
\text { culebras las niñas, decía mi } \\
\text { finada suegra. Por eso les decía } \\
\text { a las niñas: -En una visión con } \\
\text { culebra, no le tiren (piedras); si } \\
\text { la matan, mátenla bien, decía, } \\
\text { pues. -No la dejen medio viva, } \\
\text { porque le quitan el alma a la } \\
\text { gente si no matan a la culebra. } \\
\text {-Todo eso decían nuestras } \\
\text { abuelas, decía antes mi finada } \\
\text { suegra. }\end{array}$ \\
\hline
\end{tabular}

\section{Perimontun de Wenumañ}

(Narrado por Ramón Naupa Epuñán, el 24.02. 1989)

Antes había un hombre que se llamaba Huenumán, el cual era muy pobre; en verdad, no tenía ni una cosa. Una vez fue a la pinalería, a buscar piñones. Era la época cuando caen los piñones (marzo). Andaba en un caballo prestado. Cuando quiso volver a su casa, fue a buscar su caballo, pero no lo halló; se perdió. Entonces se puso a caminar, para buscarlo, pero perdió el sentido; no supo por donde andaba. Caminando llegó a un aguazal que tenía un pasto muy bonito. Ahí estaba parado su caballo. Se reanimó al verlo, pero, cuando fue a agarrarlo, se hundió. Desapareció en el aguazal. Solo vio un rastro. Cuando miró de nuevo, asomaba en el barro un cuello parecido al de un caballo, con la tusa del mismo, un poco desparramada hacia los lados. Entonces recordó que, en casos así, la gente se pinta y reza, según cuentan hombres que tienen conocimientos. Así lo hizo. Después de rezar un buen rato, sacó un cuchillo pequeño, se acercó a la tusa y le cortó despacito un manojito de crin. Luego regresó a su casa. Entonces recobró el sentido. Andaba en un campo solitario, grande, y reconoció su "puesto". Ahí cerca estaba el caballo. Volvió a su casa. Unos días después, llegó a verlo un caballero rico, el cual le dio cinco yeguas a medias, las cuales tomó. Dicen que en unos años tuvo una tropilla. Se hizo rico con la suerte que le llegó, a raíz de la visión que tuvo en la montaña. Según él, la suerte se la había dado "El que gobierna la montaña".

\begin{tabular}{|l|l|}
\hline $\begin{array}{l}\text { 0. Vey ta tüvachi ngütram } \\
\text { allküpan ta, kuyvi eypikevüy } \\
\text { tayñi ñuke em. }\end{array}$ & $\begin{array}{l}\text { 0. Resulta que esta conversa la } \\
\text { escuché antes, la decía antes } \\
\text { mi finada madre. }\end{array}$ \\
\hline
\end{tabular}

I. -Kuyvi mülerki kiñe pütta I-Antes había un hombre viejo wentru, Wenumañ pingi, piki, (que) se llamaba Huenuman, vey ta kuñivalürki, ngerkelay decía. -Era un hombre pobre, ta kullin, nielay chem no ume no tenía animales, no tenía ni kuñival wentru. una cosa el hombre pobre.

2. -Vey amurki pewen mew, 2. Entonces fue a la pinalería, a alul kineñchi pewenentu la pinalería de Alul-que está mu ngülliwalu, yattengen, sola (aislada)-, a piñonear, piki. Vey ngilliwkerki. Vey decía. Era la época cuando ya rakiduamñawkerki chumngechi están maduros los piñones ${ }^{52}$ tayñi niavel, veychi rakiduam lba siempre a recoger piñones. ñawlkerki.

Andaba pensando cómo tenerlos; con ese pensamiento andaba.

3. Veymew vemngechilu vey 3 . Entonces, así las cosas, dijo: velen -amuton, pirki, amuton -Me voy, me voy a mi casa. Fue ñi ruka mu, pirki. Veymew a buscar su caballo. Andaba amurki kintometolu tayñi trayendo un caballo prestado. kollu. Nawlkerki kiñe aretun Entonces, fue a buscar su kollu. Veymew vemngechilu caballo y no lo encontró; amulu kintumeal tayñi kollu dicen que perdió su caballo. vey peturkelay, ñamngümturki -No lo hallé, dijo. Entonces se tayñi kollu. -Petulan, pirki. puso a caminar, para buscar a Veymew vey ta vemngechilu su caballo.

amukünowürki, kintolu iñ kollu. 


\begin{tabular}{|l|l|}
\hline $4 . \quad$ Vey namturki, & 4. Entonces se perdió, perdió \\
weluduamturki, kimtulay chew & el sentido, no supo por donde \\
iñ upavel, chuchi konavel, ivey & pasaba, adonde iba, jse perdió, \\
ta ñamüy nga! Amukünowi & pues! Se puso a caminar el \\
ti wentru pewenentu mew & hombre por la gran pinalería, \\
ta tüvachi Pültrüngütron & por la montaña que se llama \\
pingechi mawida püle. & Pültrüngütron. Dicen que por \\
Veychipüle konürki & ahí entró. \\
\hline
\end{tabular}

5. Veymew powürki kiñe mallinentu mew. -Müli ko, pirki, -na kümelkali kachu. Veymu powlu inche powkintupon, veymu utrali iñ kollu, pirki.Vey yavüduamürki. -Pen iñ kollu, pirki. Vey amurki nga nümeal iñ kollu, welu ta ñamnagtuy ti kollu piam nga. -Epe powlu inche ñamnagtuy iñ kollu, pirki. Petulay.

5. Entonces llegó hasta un aguazal ${ }^{53}$.-Había agua (y) estaba muy bonito el pasto, decía. -Cuando llegué allá, fui a mirar; ahí estaba parado mi caballo, decía. Entonces recuperó el ánimo. - Encontré mi caballo, dijo. Fue a agarrar su caballo, pero dicen que el caballo desapareció. -Casi había llegado, (cuando) desapareció (en el aguazal) mi caballo, decía. No lo halló.

6. Veymew vemngechilu vey amukarki chew tayñi mülepim tati kollu nga. -Veymu pepon kiñe pünon kollu, pipingi, -kiñe pünon müten, doy ngelay, veymew kintun veymu, pipingi ti wentru. Vey vemngechilu vey -ká powkintun, pirki, -wevpali kiñe topel kollu küchili, pirki, -votrantu mew. Vey -kellpaytripalepay tayñi tusa, pirki, -ta ti kollu püchin müten.

7. Veymew vemngechilu vey pütta wentru kay nga ti vey püchiken allkütupakerki ta dungu tayñi piken ta doy kimke wentru vey tayñi kolongtungeken, tayñi ngillatungeken vey tayñi suerteken pu che veymu poyen vey, pirki. Vey ngillaturki.

8. Avkentu ngillatulu vey 8 . Después de rogar un buen -ñawlün kiñe püti kuchillu, rato, y como andaba trayendo pipingi. Vantey ti kuchillu, un cuchillito -era así nomásngüdüvtukulyawlki. Vey en el cinturón, saqué mi -entupan iñ kuchillu vey cuchillo y despacito me le ñochikechi kontuviñ ti acerqué a la tusa del caballo, tusa kollu, pipingi. Vey piam decía. Dicen que le cortó un katrüñmaturkevi kiñe püchi manojito de crin, de la crin del pada ta kilin, kilinkollu. caballo. -Se lo corté despacito, -Ñochikechi katrüñmaviñ, decía. Entonces, después que pipingi. Vemngechilu se lo sacó, se volvió (a su casa). entuñmavilu vey küpatuy.
9. -Vey kimkonlu reke 9. -Luego, como que recobré vemngechitun, pipingi. -Pütta otra vez el sentido, decía. üwemapu mew ñawkerken ta -iAndaba por un campo ti, pipingi. -káa adentun chew grande solitario!, decía. iñ mülen tayñi puehtu vey -Reconocí otra vez donde amutun vey püchitripa puehtu estaba mi 'puesto' y me fui. mülekarki kollu nga, pipingi ti Cerca del 'puesto' estaba pütta wentru.Vey küpatuy.

todavía el caballo, decía el hombre. Se volvió (a su casa).
10. Vey nga akutulu tamew muvün entu mu müten piam admay kiñe ülmen vey elungi piam kechu yegua 'a mediah', elurkeyu ti ülmen. Vey nüy. -Veymokan müten, pi piam ti pütta wentru vey muvün tripantu mew velechi pütta tropiya nii piam.
10. Después que volvió aquí, dicen que en pocos días nomás llegó donde él un caballero rico y le dio cinco yeguas a medias. (Las) tomó. -Con eso me bastó, dijo el hombre. Dicen que en unos años tuvo una tropilla grande.

I I.Vey vemngechi pen tüvachi II-Así hallé esta suerte, dicen suerte, piki piam tati wentru, que decía ese hombre, que se pütta Wenuman pingevüy em. llamaba Huenumán. Se hizo Vey ülmeni. -Vey vemngechi rico. -Así me llegó la suerte, adman ta suerte, piki piam conversaba. Tuvo una visión tayñi ngütram. Perimontuy en la cordillera grande. -Me la piam pütta degiñ mew. -Vey dio (la suerte) El que gobierna ta mawida ngünechen an ta la montaña, conversaba, elulaanu ve, piki piam tayñi según dicen ¡Hasta aquí llega, ngütram. ¡Ventepoy, peñi!. hermano!

\section{CONCLUSIÓN}

El perimontun ha sido experimentado por miembros de la comunidad de Cauñicú, en el pasado y en el presente. Cualquier persona puede vivirlo, en el momento menos esperado. Algunos episodios son alucinantes $y$, cuando son narrados, quienes los oyen, sobre todo los niños, guardan completo silencio. Es interesante enterarse de que el wekuvü que interviene en un perimontun no es siempre un ente malo, peligroso que, incluso, puede causar la muerte, como ha sido considerado tradicionalmente en la cultura mapuche, sino que también puede ser favorable para quien tiene la "visión", dándole, por ejemplo, buena suerte.

Agradecimientos: agradecemos a las personas de la comunidad de Cauñicú que narraron las "visiones", cuyos nombres consignamos. Ellas no solo nos ofrecieron su generosa hospitalidad, sino también confiaron en nosotros al entregarnos aspectos de su cultura comparativamente poco conocidos, de gran valor. 


\section{NOTAS}

I "Perimuntun, llaman también una gran muchedumbre de gente, o de otra cosa, que no la pueden contar" y "Perimuntumapun, agorar mal de la tierra, como que le vendrá algún daño" (Valdivia 1606, Vocabulario).

2 El autor incluye un verbo perimolquen -omen, signum adesse mortis, calamitatis, ostenta videri, dare praesagium, enuntiationem, praedictionem (Havestadt 1883, Chilidúgu I: 537, p. 457), que los otros dos gramáticos coloniales no consignan. Además, según el mismo misionero, perimontu significaba también 'cuerpos celestes', 'fenómenos de la naturaleza': Quid habes dicendum de aere? paucis dicam. Elementum est, in quo respiramus, ac spiritum ducimus, impletque omne illud spatium, quod coelum terramque interjacet, \& in quo Naturae illa miracula fiunt, quae meteora dicimus. Chemchi dgu gei crù? Elemento gei veimo lihuetuiñ, opulbi vill huellin rangiclelu Huenu mo Tue mo cai. Veimo vemgequeign Naturaleza ñi perimontu ica Huenu mo ta iñ pequeel. ¿Qué cosa es el aire? Es un elemento con que respiramos, llena todo el espacio que hay entre el cielo y la tierra. Por eso son así los fenómenos de la naturaleza que vemos en el cielo [traducción nuestra del texto en mapudungun, el cual difiere algo del texto en latín] (Havestadt I883, I: n³43 Caput II DE AERE, p.200). (Véase también, al respecto, $n^{\circ} 344$ y ss.).

3 Los léxicos coloniales del mapuche consignan para "salvador" montulvoe, montulchevoe, montulcavoe. Actualmente se dice montulchefe. Pensamos que la palabra perimontu no se compone de pen y montu. Si así fuera, la palabra sería pemontu. Por otra parte, no existe un morfema peri constituyente de palabras. La palabra perimontu no puede descomponerse.

4 "I.Wëne mëlei tëfachi perimontundëju. Kiñeke che fei pikeinn "Perimontun mëlei feichi mapu meu - konümpanekei mapu cheu ñi mëlen -penei, piam, kiñe wentru, fei nütramkei afmatufalchi dënu pikeinn. "Naqpai piam kiñe kurü toro, tripapai pillañ meu, nentualu lafken, pikei, pikeinn". Primero está este asunto de la visión. Algunas personas dicen que hay visiones en la tierra. Se menciona la tierra donde hay. Dicen que se ha visto a un hombre que habla de cosas sorprendentes. Dicen que, según él, bajó un toro negro que salió del volcán, el cual va a hacer salir el mar". 2. Ká perimontulu "nemen wenu mapu" pikei; kanelu "dënui waka", pi, "dënueneu ñi [ikiñe?] pëllü” pikei piam. "Chumnelu entulaimn kawiñ? Chumnelu jillatukeimn? pinen”, pikei feichi perimontulu". Otro que tuvo una visión dice:"Fui a dar al cielo"; otro dice:"Me habló una vaca”; otro dice:"Me habló mi [¿un?] espíritu”."¿Por qué no celebran la fiesta?, ¿por qué no hacen rogativa?, se me dijo", dice el que tuvo la visión”. (Coña 1973: 372). La traducción al español es nuestra.

5 Según el peñi Basilio Porteño, hay wekuvï bueno y wekuvü malo: Epuli wekuvü, kiñe küme wekuvü ka kiñe weya wekuvü, piki püttake che yem. Tüvichi azul vey küme wekuvü; tüvichi kelü wekuvü veyta ti weya wekuvü. Tüvichi küme wekuvü küme pewmangi ka pütta ngillanii, suerte uli, kümeke dungu piam:"Hay dos wekuvü, un wekuvï bueno y un wekuvü malo, decían los finados mayores (antepasados). El azul es un wekuvï bueno; el rojo es un wekuvï malo. El wekuvü bueno da buena suerte, cosas buenas, según dicen".

6 Véase La mujer culebra, en Sánchez 1989.
7 Véase en Augusta 1910. Textos recogidos por el R. P. Fray Sigifredo de Fraunhaeusl en Panguipulli [...]: 276 - 40I.

8 Veymew veymu puede traducirse por 'entonces', 'por eso', 'luego','después', 'ahi'; vey por 'entonces', 'luego', 'y'; vey ta por 'resulta que'; vey vemngechilu, vey vemngechilu vey por 'así las cosas'.

$9 \quad$ Che üy, nombre individual que reciben los niños de la comunidad, de ambos géneros, algunos días después de su nacimiento, el cual conservan durante toda la vida. Likanan = likan 'cuarzo blanco' y antü 'sol'.

10 "em, (yem después de vocales), suf. : expresa pesar, recuerdo doloroso, compasión, ternura, admiración, o que una persona, cosa o cualidad ha dejado de existir; v.g.: $\tilde{\tilde{N}} \mathbf{i}$ chau em mi finado padre" (Augusta 1916, Diccionario I: 40).

II El verbo kulngen -antes culmen-significaba 'desear con ansias', 'codiciar' (Febrés I765, Calepino: 465).

12 Wingkañma wentru'mapuche achilenado'."winkañma (wentru), s., indígena españolizado" (Augusta 1916, Diccionario I: 26I). El verbo wingkawün significa 'achilenarse', 'convertirse en chileno'. Ha dado la forma españolizada ahuincarse.

13 Era una excelente narradora y le transmitió muchos relatos a su hijo Ramón. Se llamaba Rosa Epuñán.

14 En el mes de marzo. Entonces se celebra también, cada año, una 'rogativa' (ngillatun).

15 'Recoger piñones', los cuales, ya maduros, caen espontáneamente de los árboles.

16 Kollu en vez de kawellu 'caballo'. Se usa habitualmente en Cauñicú. Ocurre también en otros relatos.

17 De pipingen 'decir o repetir siempre lo mismo', ocurre frecuentemente en el relato oral. Lo traducimos simplemente por 'decía'.

18 En rigor, kumüñ es una palabra antigua que significaba 'mortaja': “[...]Cùmuñ -mortaja (Febrés 1765, Calepino : 473, y Febrés 1765, Vocabulario: 372); "Emortale lineum, indusium funebre, ferale amiculum, cùmun, cùlmun" (Havestadt 1883, Chilidúǵ I, \# 537, p. 458). Es posible que el cuerpo estuviera sobre una especie de ataúd, llamado pulluiay (Febrés 1765, Vocabulario: 313 ).

19 Verbo usual por 'huir','arrancar'; leventun, en chedungun. Literalmente, le seguía la(s) espalda(s).

Lo hacía girar (sobre su cabeza).

Lenga o roble blanco (Nothofagus pumilio).

23 Koyam sgnifica 'roble' (Nothofagus obliqua), pero en el relato 'árbol', en general.

24 Küla (Chusquea quila), la gramínea quila. El nombre aparece con pronunciación española en el relato.

25 La forma interrogativa equivale a una afirmación.

26 Había llegado a una pinalería.

$27 \quad$ En rigor no eran hachas (toki, kachal); trülev (kura) era una piedra tableada con filo, según R. Naupa.

28 Quilquil (Glaucidium nanum), llamado también chonchón o tuétué. Se lo relaciona con la brujería.

29 Según Alonqueo (1985: I10) "Chayankadi - ser de las costillas peladas y transparentes- es el Witranalwe (cuerpo resucitado con alma distinta)".

30 "Carùlan, cadùlan - muerte, y morir a cuchilladas, ò puñaladas, y de repente" (Febrés 1765, Calepino: 439). Actualmente el verbo significa, según Augusta, 'morir repentinamente, pero de una enfermedad'(1916, Diccionario I:77).

31 Las referencias sobre los kovkeche, 'hombres del pan', son 
-hasta donde estamos informados- escasas. En el cuento EI hijo del oso, incluido en los Estudios Araucanos del Dr. Lenz ( $1895-1897: 27$ I), el protagonista llega donde un cacique de los "hombres del pan". Un cheruve casi exterminó a esos hombres. Según Lenz, eran probablemente del tamaño de un pan, enanos, pigmeos, y vivían en un país subterráneo. Según M. Grebe \& S. Pacheco (1972: 49 - 5I), en el minche mapu -zona oscura, extraña y caótica-, residen junto a los espíritus maléficos (wekufe) los hombres enanos o pigmeos (Iaftrache). El minche mapu es llamado también laftrache mapu (tierra de la gente pequeña) y kovkeche mapu (tierra de la gente del pan). Según contaba el padre, o el abuelo, de M.Linai-de la comunidad de Cauñicú- antes había unos hombrecitos que vivían debajo de la tierra, los cuales se alimentaban con el vaho de la comida. Don Carmelo Pavián contaba lo mismo, y agregaba que, por alimentarse así, "hacían solo molido, líquido", es decir, jsolo orinaban! En el relato que consignamos, la tierra subterránea estaba iluminada.También en otro relato de los 'hombres del pan' que recolectamos. ¿Se relacionarían con los kofkeche 'prearaucanos', propuestos por el Dr. Dillman Bullock? ¡No podemos pronunciarnos al respecto!

32 En el relato Las apuestas, recopilado por el Dr. Lenz, los kovkeche eran exterminados por un cheruve (1895I897: 27I).

33 Wenumañ= wenu 'cielo' y mañke 'condor' (Vultur gryphus).

34 La comunidad sufría hambre, por falta de alimentos, sobre todo durante el riguroso invierno cordillerano.

35 Llamado también 'diente de león', 'lechuguilla', 'chinita el campo' (Taraxacum officinale Weber). Es comestible y medicinal.

36 Hijo e hija de la madre.

37 ¿Apreciada"? "shakin, tr., honrar, respetar, apreciar. | adj., apreciable" (Augusta 1916, Diccionario I: 209).

38 Actualmente significa en Cauñicú 'tía paterna'.

39 Lobo-ba: arisco, huidizo, montaraz, alzado.

40 Piñón que se conserva en un hoyo lleno de agua corriente, durante una o más temporadas (según las necesidades de consumo), en cantidades importantes. Según el cronista Diego de Rosales (1877), los piñones podían mantenerse frescos durante cuatro y cinco años (p. 192). El nombre proviene de dollümün 'agujerear [hacer un hoyo]' y ko 'agua' (Veáse Febrés 1765, Calepino :478).

41 Se trata de un cheruve, ser antropófago de la cordillera. Véase Perimontun del pewenche que estuvo en la casa del cheruve, en Sánchez 1989, y Perimontun del hombre que viajó a la Argentina a buscar yerba mate, en Sánchez 1996.

42 “Ran -la apuesta en el juego" (Febrés I765, Calepino: 6I8).

43 Pantano hondo y peligroso para humanos y animales. Suele estar cubierto por vegetación. La palabra se emplea en español.

44 Puesto: lugar asignado a una familia de la comunidad, en la pinalería o en una 'veranada' (adonde son llevados los animales a pastar en el verano).

45 Según el narrador el wekuvü puede ser también bueno. Véase nota $\mathrm{N}^{\circ} 5$.

46 Licor que se obtiene de piñones (ngülliw) sancochados y molidos. Se emplea en el püntevün y en el ngillatun. Entonces es llamado ngolngol.

47 Rogativa que se lleva a cabo cuatro veces en el año. Dos de ellas tienen carácter comunitario (en los meses de agosto y octubre) y dos lleva a cabo el dueño de casa, en la respectiva familia (en fechas diferentes). En este caso se denomina püchi püntevün (pequeño püntevün). Esta denominación significa 'asperjar', 'aspersión'. Oraciones del püntevün -y también del ngillatun-pueden verse en Sánchez 200I2002.

48 Llovtuy '(el, ella) aguaitó', 'acechó' (tercera persona del verbo llovtun).

49 'Suegra de la esposa' y también 'nuera'.

50 Árbol caducifolio nativo del bosque andino del sur de Chile y de Argentina (Nothofagus antarctica). Se denomina también haya antártica.

51 Perimontucar es españolización usual de perimontun (como guillatucar 'rogar', 'celebrar rogativa', de ngillatun; machitucar 'medicinar', de machitun; pañitucar 'tomar la resolana', de pañütun, etc.).

52 En el mes de marzo.

53 Mallin (ko), mallinentu 'aguazal'. Mallin, lacuna, palus udis” (Havestadt I883, Chilidúgu II: 709).

\section{BIBLIOGRAFÍA}

Alonqueo, M. 1985. Mapuche AYER HOY. Imprenta y Editorial San Francisco, Padre Las Casas.

Augusta, F. J. de. 1916. Diccionario Araucano-Español y Español-Araucano, tomos I y II. Imprenta Universitaria, Santiago.

Bacigalupo, A. M. 200I. La Voz del Kultrun en la Modernidad. Tradición y Cambio en la Terapéutica de Siete Machi Mapuche. Ediciones Universidad Católica de Chile, Santiago.

Coña, P. 1973. Memorias de un Cacique Mapuche. ICIRA, Santiago.

Faron, L. 1964. Hawks of the Sun. Mapuche Morality and its Ritual Attributes.University of Pittsburg Press, Pittsburgh.

Febrés, A. 1765. Arte de la Lengua General del Reyno de Chile, con un Diálogo Chileno-Hispano Muy Curioso: A que se Añade la Doctrina Christiana, esto es, Rezo, Catecismo, Coplas, Confesionario, y Pláticas; lo más en Lengua Chilena y Castellana: y por fin un Vocabulario HispanoChileno, y un Calepino Chileno-Hispano más copioso. Compuesto por el $P$. Andrés Febres Misionero de la Comp. De Jesus. Año de 1764. [...] Con Licencia: en Lima, en la calle de la Encarnación. Año de 1765.

Grebe, M. \& S. Pacheco. 1972.“Cosmovisión mapuche”. Cuadernos de la Realidad Nacional, 14: 46-73.

Guevara, T. 1908. Psicolojía del Pueblo Araucano. Imprenta Cervantes, Santiago.

Havestadt, B., [ 1777] 1883. Chilidúǵu sive Tractatus Linguae Chilensis opera Bernardo Havestadt. Editionem novam inmutatam curavit Dr. Julius Platzmann. 2 vols. In aedibus B.G. Teubneri MDCCCLXXXIII, Lipsiae.

Koessler-IIg, B., 1962. Tradiciones Araucanas. Tomo I. Instituto de Filología, Universidad Nacional de La Plata.

Latcham, R., 1922. La Organización Social y las Creencias Religiosas de los Antiguos Araucanos. Publicaciones del Museo de Etnología y Antropología de Chile. Tomo III (2, 3 y 4). Imprenta Cervantes, Santiago.

Lenz, R., 1895-1897. Estudios Araucanos. Materiales para el Estudio de la Lengua, la Literatura i las Costumbres de los Indios Mapuche o Araucanos. Diálogos en Cuatro Dialectos, Cuentos 
Populares, Narraciones Históricas i Descriptivas i Cantos de los Indios de Chile en Lengua Mapuche, con Traducción Literal Castellana... Imprenta Cervantes, Santiago.

1905-1910. Diccionario Etimolójico de las Voces Chilenas Derivadas de Lenguas Indíjenas Americanas. Imprenta Cervantes, Santiago.

Rosales, D. de. 1877. Historia General de el Reyno de Chile FlandesIndiano [...]. (Tomo I). Imprenta del Mercurio,Valparaíso.

Sánchez, G., 1989. "Relatos orales en pewenče chileno". AUCh 17: 289-360.

-1996. "Relatos orales mapuches (procedentes del Alto Bío-Bío,VIII Región”). Boletín de la Academia Chilena (de la Lengua) 7I: 289-30I.

---2 200 I-2002. “Oraciones rituales en pewenche chileno. Ritos ngillatun y püntevün”. Revista Chilena de Antropología I6: I 3 I164.

Titiev, M. 195I. Araucanian Culture in Transition. Occasional Contributions from the Museum of Anthropology of the University of Michigan $N^{\circ} 15$. University of Michigan Press. Ann Arbor.

Valdivia, L. de, 1606. Arte y Gramatica General de la Lengva Qve corre en todo el Reyno de Chile, con vn Vocabulario, y Confessonario. Compuestos por el padre Luys de Valdiuia de la Compañía de lesus en la Prouincia del Piru [...] Con Licencia. En Lima por Francisco del Canto. Año. 1606. 